TP Periodica Polytechnica

42(2), pp. 131-138, 2014

DOI:10.3311/PPtr.7509

Creative Commons Attribution (1)

RESEARCH ARTICLE

\section{The Aero-Thermodynamic Possibilities of Increasing Turbocharging Efficiency}

Endre Pásztor

RECEIVED 2 MAY 2014

\section{Abstract}

Turbocharging is a basic possibility to increase the utilization of reciprocating internal combustion engines. It can be stated that reciprocating engines of more than $100 \mathrm{~kW}$ nominal power are oftenequipped with turbochargers and in most of the cases they also feature an intercooler. In order to be able to investigate the possibility of turbocharger development, one has to thoroughly discover the methods for improvement.

In the present article an investigation is carried out to obtain the dependence of efficiency of turbocharging on the aerothermodynamic properties of the turbocharger. Present paper covers partially - as an overview - the previous results of turbocharger development while its aim is to provide guidelines for the possible upper limits of turbocharging in the automotive industry. The research does not include special fields of application (e.g. racing engines with extremely high acceleration) with especially highly supercharged reciprocating engines.

In order to reduce the complexity of the relationships under investigation only those parameters are considered as variables that have a significant effect on the efficiency of turbocharging.

\section{Keywords}

increase of indicated mean pressure · pressure ratio of turbocharger compressor $\cdot$ losses of compressor and turbine

\section{Endre Pásztor}

Department of Aeronautics, Naval Architecture and Railway Vehicles, Budapest University of Technology and Economics e-mail:pasztor@vrht.bme.hu
List of symbols (in the order of first appearance)

\begin{tabular}{|c|c|c|}
\hline Symbol & Unit & Description \\
\hline$\pi_{c}$ & - & Compressor pressure ratio $\left(p_{2} / p_{1}\right)$ \\
\hline$p_{i 0}$ & $\mathrm{~N} / \mathrm{m}^{2}$ & $\begin{array}{l}\text { Indicated mean pressure of the basic } \\
\text { engine without turbocharging }\end{array}$ \\
\hline$\eta_{m m}$ & - & $\begin{array}{l}\text { Mechanical efficiency of turbocharged } \\
\text { engine }\end{array}$ \\
\hline $\mathrm{p}_{\text {icht }}$ & $\mathrm{N} / \mathrm{m}^{2}$ & $\begin{array}{l}\text { Indicated mean pressure of turbo- } \\
\text { charged engine without intercooler }\end{array}$ \\
\hline $\mathrm{p}_{i}$ & $\mathrm{~N} / \mathrm{m}^{2}$ & General indicated mean pressure \\
\hline $\mathrm{V}$ & $\mathrm{m}^{3}$ & piston displacement \\
\hline $\mathrm{n}$ & $1 / \mathrm{s}$ & rotation speed of engine \\
\hline $\mathrm{W}_{\text {eff }}$ & $\mathrm{J}$ & effective work \\
\hline$\eta_{\text {eff }}$ & - & effective efficiency \\
\hline $\mathrm{Q}_{\text {in }}$ & $\mathrm{J}$ & heat added during the process \\
\hline $\mathrm{B}_{\text {in }}$ & $\mathrm{kg}$ & fuel added to the process \\
\hline $\mathrm{C}_{\mathrm{f}}$ & $\mathrm{J} / \mathrm{kg}$ & calorific value of the fuel \\
\hline $\mathrm{m}_{\mathrm{a}}$ & $\mathrm{kg}$ & mass of air charge \\
\hline$\alpha$ & - & air-fuel ratio \\
\hline $\mathrm{L}_{\mathrm{a}}$ & $\mathrm{m}_{\mathrm{a}} / \mathrm{B}_{\text {in }}$ & stoichiometric ratio \\
\hline$\rho$ & $\mathrm{kg} / \mathrm{m}^{3}$ & density \\
\hline$\eta_{t}$ & - & thermodynamic efficiency \\
\hline$\eta_{i}$ & - & indicated efficiency \\
\hline $\mathrm{p}_{\text {ich }}$ & $\mathrm{N} / \mathrm{m}^{2}$ & $\begin{array}{l}\text { indicated mean pressure of basic work } \\
\text { cycle }\end{array}$ \\
\hline $\mathrm{n}_{\mathrm{c}}$ & - & polytropic exponent of compression \\
\hline$\eta_{\text {polc }}$ & - & polytropic efficiency of compression \\
\hline$\sigma_{01}$ & - & $\begin{array}{l}\text { pressure loss factor of intake duct } \\
\text { upstream of turbocharger compressor } \\
\left(\sigma_{01}=p_{1} / p_{0}=0.98\right)\end{array}$ \\
\hline $\mathrm{p}_{0}$ & $\mathrm{~N} / \mathrm{m}^{2}$ & ambient pressure $\left(p_{0}=10^{5} \mathrm{~N} / \mathrm{m}^{2}=1 \mathrm{bar}\right)$ \\
\hline $\mathrm{T}_{0}$ & $\mathrm{~K}$ & ambient temperature $\left(T_{0}=298 \mathrm{~K}\right)$ \\
\hline $\mathrm{T}$ & $\mathrm{K}$ & general temperature \\
\hline$\kappa_{\mathrm{a}}$ & - & isentropic exponent of air \\
\hline$\eta_{\text {is } C}$ & - & isentropic efficiency of compressor \\
\hline$\rho_{2}^{*}$ & $\mathrm{~kg} / \mathrm{m}^{3}$ & $\begin{array}{l}\text { density of engine intake air using } \\
\text { intercooler }\end{array}$ \\
\hline $\mathrm{T}_{2} *$ & $\mathrm{~K}$ & $\begin{array}{l}\text { engine intake air temperature using } \\
\text { intercooler }\end{array}$ \\
\hline$\phi$ & - & effectiveness of intercooler (efficiency) \\
\hline
\end{tabular}




\begin{tabular}{|c|c|c|}
\hline $\mathrm{R}$ & $\mathrm{J} / \mathrm{kgK}$ & $\begin{array}{l}\text { specific gas constant of working } \\
\text { medium }\end{array}$ \\
\hline $\mathrm{p}_{\mathrm{iex}}$ & $\mathrm{N} / \mathrm{m}^{2}$ & $\begin{array}{l}\text { medium } \\
\text { indicated mean pressure of scaveng- } \\
\text { ing and back pressure of engine with- } \\
\text { out intercooler }\end{array}$ \\
\hline $\mathrm{p}_{\text {iex }} *$ & $\mathrm{~N} / \mathrm{m}^{2}$ & same as $p_{i e x}$, but with using intercooler \\
\hline$\sigma_{22^{*}}$ & - & pressure loss factor of intercooler \\
\hline $\mathrm{p}_{\text {icht }}{ }^{*}$ & $\mathrm{~N} / \mathrm{m}^{2}$ & $\begin{array}{l}\left(\sigma_{22^{*}}=p_{2} * / p_{2}=0.99\right) \\
\text { final indicated mean pressure of } \\
\text { turbocharged engine with intercooler }\end{array}$ \\
\hline $\mathrm{W}_{\mathrm{c}}$ & $\mathrm{J}$ & work requirement of compressor \\
\hline $\mathrm{W}_{\mathrm{t}}$ & $\mathrm{J}$ & delivered work of turbine \\
\hline $\mathrm{c}_{\mathrm{pg}}$ & $\mathrm{J} / \mathrm{kgK}$ & $\begin{array}{l}\text { isobaric specific heat of gas entering } \\
\text { the turbine }\left(c_{p g}=1200 \mathrm{~J} / \mathrm{kgK}\right)\end{array}$ \\
\hline $\mathrm{c}_{\mathrm{pa}}$ & $\mathrm{J} / \mathrm{kgK}$ & $\begin{array}{l}\text { isobaric specific heat of air entering } \\
\text { the compressor }\left(\mathrm{c}_{\mathrm{pa}}=1005 \mathrm{~J} / \mathrm{kgK}\right)\end{array}$ \\
\hline $\mathrm{m}_{\mathrm{g}}$ & $\mathrm{kg}$ & $\begin{array}{l}\text { mass of exhaust gas entering the } \\
\text { turbine }\end{array}$ \\
\hline$\eta_{\mathrm{m}}$ & - & mechanical efficiency of turbocharger \\
\hline$\pi_{\mathrm{T}}$ & - & turbine pressure ratio $\left(\pi_{T}=p_{3} / p_{4}\right)$ \\
\hline$\eta_{\text {is } \mathrm{T}}$ & - & isentropic efficiency of turbine \\
\hline$\kappa_{\mathrm{g}}$ & - & $\begin{array}{l}\text { isentropic exponent of combustion } \\
\text { gases }\end{array}$ \\
\hline$\eta_{\text {istot }}$ & - & $\begin{array}{l}\left(\kappa_{g}=1.3\right) \\
\text { total efficiency of turbocharger }\end{array}$ \\
\hline$\sigma_{45}$ & - & $\begin{array}{l}\left(\eta_{i s ~ t o t}=\eta_{i s C} \cdot \eta_{i s T} \cdot \eta_{m}\right) \\
\text { pressure loss factor of exhaust system }\end{array}$ \\
\hline & & $\left(\sigma_{45}=p_{5} / p_{4}=0.98\right)$ \\
\hline $\mathrm{P}$ & - & $p_{\text {icht }}^{*} / p_{\text {icht }}$, notation on Fig. 7 \\
\hline
\end{tabular}

\section{Introduction, posing the problem basic considerations}

In order to be able to determine the possibilities for the efficiency increase of the turbocharged internal combustion reciprocating engines (henceforth turbocharged engines), it is important to investigate what is the extent to which present parameters of turbocharging allow further development.

The efficiency of turbocharging depends appreciably on the various losses arising in the compressor and exhaust turbine (generally, in the supercharging system), on the $\pi_{c}=p_{2} / p_{1}$ pressure ratio of the compressor, on the $t_{3}$ exhaust gas temperature, and on the parameters of the increasingly applied intercooler. The analysis covers the investigation of the possibility of cross scavenging, where the maximum attainable efficiency is approached with cutting edge technology including rotating heat exchangers. To increase the understandability of the study the reciprocating engine is investigated with simplified conditions in some extent. According to this, the development of oscillatory phenomena in the supercharged engine is not taken into consideration. This approximation does not influence the ascertainments; however, it results in a clearer article.

The parameters, which affect the turbocharging in a large extent, are varied within the present realistic ranges; nevertheless,

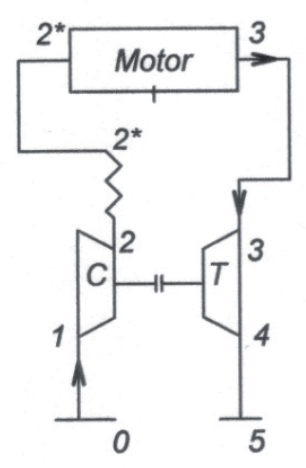

Fig. 1. Operational schematic of turbocharged engine Thermodynamic stations: 0 - upstream of intake duct; 1 - upstream of compressor; 2 - compressor discharge; $2 *$ - intercooler exit; 3 - downstream of engine (turbine inlet); 4 - turbine discharge; 5 - downstream of exhaust duct

it is also shown how far the efficiency of turbocharging may be increased with the anticipatory future peak values (Shiwale et. al, 2013). The factors, whose effect is less or negligible, are taken into account as their realistic, constant value. These considerations are clearly represented in the calculations as well as in the list of symbols.

The schematic of the turbocharged engine and the substantial thermodynamic stations are shown on Fig. 1. The investigations are henceforth carried out according to the notations of Fig. 1. In this figure the outline for intercooler is also represented. Without intercooler the stations 2 and $2 *$ are implicitly the same.

In the present paper we do not make a distinction between gasoline and diesel engines, as there is no difference in thermodynamic aspects between the two types of engines. Our investigation is carried out supposing a real, maximal thermally loaded condition.

Our analysis is started with a basic engine without supercharging having an indicated mean pressure of $p_{i 0}$ and the goal is to establish the correlation between increasing indicated mean pressure of the turbocharged engine and the various conditions of turbocharging. We do not include the survey for the change of effective mean pressure as the $\eta_{m m}$ mechanical efficiency can be upgraded by 2 or 3 percent under optimal conditions due to supercharging. The conformation of $\eta_{m m}$ is particularly important at part power settings (Pásztor, 1970) but it is not taken into account.

In the figure representing the results of the equation system the ratio of $p_{i c h t} / p_{i 0}$ is indicated.

In our study first the theoretical background of turbocharging is discussed, and the equations for computation are determined, respectively; finally the results are demonstrated. In the present paper investigations about instable operational modes are not covered, as it is included in various domestic and foreign literatures (Beneda, 2013; Boyce, 1993; Kalabic et. al., 2011). 


\section{Equation system}

\subsection{Increase of indicated mean pressure of the main cycle}

Our considerations are started with an equation that is applicable to engines regardless of the presence or absence of supercharging (Pásztor and Szoboszlay, 1967). Effective work of the engine can be calculated as:

$$
W_{\text {eff }}=p_{i} \cdot V \cdot \eta_{m m}
$$

The effective work $W_{\text {eff }}$ is also expressed as the product of effective efficiency and introduced heat:

$$
W_{\text {eff }}=\eta_{\text {eff }} \cdot Q_{\text {in }}=\eta_{\text {eff }} \cdot B_{\text {in }} \cdot C_{f}
$$

The amount of supplied fuel can be obtained as:

$$
B_{i n}=\frac{m_{a}}{\alpha \cdot L_{a}}
$$

The indicated mean pressure of the main thermodynamic cycle can be represented from Equations (1), (2) and (3), including the definition of density $(\rho)$ :

$$
p_{i}=\rho \cdot \frac{\eta_{e f f} \cdot C_{f}}{\alpha \cdot \eta_{m m} \cdot L_{a}}
$$

Examining Equation (4) it is evident that the indicated mean pressure of the main cycle, or its growth respectively, is only depending on the density of the intake air. From the other factors, $\eta_{\text {eff }}$ has reached its practical limits already; the $\alpha$ fuel-air ratio cannot be decreased under the unity neither in the aspects of combustion engineering or without the risk of sudden damage to the engine; $L_{a}$ and $C_{f}$ is adjustable only in minimal extent supposing liquid or gaseous fuels.

The $p_{\text {ich }}$ indicated mean pressure of the supercharged cycle can be expressed in accordance with the notations of Figure 1:

$$
p_{i}=\rho \cdot \frac{\eta_{e f f} \cdot C_{f}}{\alpha \cdot \eta_{m m} \cdot L_{a}}
$$

\subsection{Determination of $\rho_{2}$ intake air density}

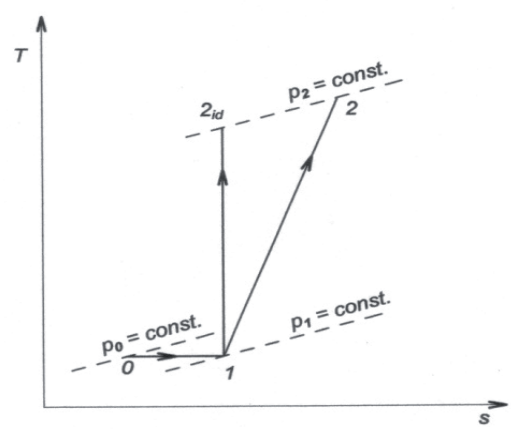

Fig. 2. T-s diagram of compression process
In view of compressor inlet parameters $\left(p_{0} ; T_{0} ; \rho_{0}\right)$ the $\rho_{2}$ real density (Figure 2) of the air supplied to the supercharged engine without intercooler can be obtained taking $n_{c}$ and $\eta_{\text {polc }}$ factors into account as follows:

$$
\rho_{2}=\rho_{1} \cdot\left(\pi_{c}\right)^{\frac{1}{n_{c}}}=\frac{\sigma_{01} \cdot p_{0}}{R \cdot T_{0}} \cdot\left(\pi_{c}\right)^{1-\left(\frac{\kappa_{a}-1}{\kappa_{a}}\right) \cdot \frac{1}{\eta_{p o l c}}}
$$

Using the isentropic efficiency of the compression process one gets:

$$
\rho_{2}=\rho_{1} \cdot \pi_{c} \cdot \frac{T_{1}}{T_{2}}=\rho_{1} \cdot \pi_{c} \cdot \frac{1}{1+\left[\left(\pi_{c}\right)^{\frac{\kappa_{a}-1}{\kappa_{a}}}-1\right] \cdot \frac{1}{\eta_{i s c}}}
$$

The relationship between $n_{c} ; \eta_{p o l c}$ and $\eta_{i s c}$ can be expressed as:

$$
\eta_{i s c}=\frac{\left(\pi_{c}\right)^{\frac{\kappa_{a}-1}{\kappa_{a}}-1}}{\left(\pi_{c}\right)^{\frac{\kappa_{a}-1}{\kappa_{a}} \cdot \frac{1}{\eta_{p o l c}}}-1}
$$

It depends on the task to be resolved, which of the three loss factors should be utilized. With large $\left(\pi_{c}>5\right)$ pressure ratios the usage of $n_{c}$ and $\eta_{p o l c}$ is practical as they are independent of the $\pi_{c}$ pressure ratio (Bosnjakovic, 1972).

Taking into account that the realized pressure ratio in turbocharger compressors is moderate $\left(\pi_{c} \approx 2-4\right)$ where $\eta_{i s c} \approx \eta_{p o l c}$, and considering that compressor maps are often showing values of $\eta_{i s c}$ (Mayer, 1996a), henceforth the isentropic efficiency is used.

\subsection{Determination of the density of the intercooled compressed air}

With the cooling of the compressed air the indicated mean pressure can be significantly augmented through the increase in density. In turbocharged engines equipped with intercooler the $\rho_{2}{ }^{*}$ density of intake air is the following according to Figure 1:

$$
\rho_{2}=\frac{\sigma_{01} \cdot p_{0}}{R \cdot T_{2}^{*}} \cdot \pi_{c}
$$

where $T_{2}{ }^{*}<T_{2}$ depending on the $\varphi$ efficacy of the intercooler.

Using the definition of intercooler efficiency we can obtain the value for $T_{2}^{*}$, supposing ambient air as cooling medium.

$$
\phi=\frac{T_{2}-T_{2}^{*}}{T_{2}-T_{0}} ; T_{2}^{*}=T_{2} \cdot(1-\phi)+\phi \cdot T_{0}
$$


The $\rho_{2}{ }^{*}$ density downstream of the intercooler can be expressed using Equations (6); (8) and (9):

$$
\begin{aligned}
\rho_{2}^{*} & =\frac{p_{2}^{*}}{R \cdot T_{2}^{*}}=\frac{\sigma_{01} \cdot p_{0} \cdot \pi_{c} \cdot \sigma_{22^{*}}}{R \cdot\left[T_{2} \cdot(1-\phi)+\phi \cdot T_{0}\right]} \\
& =\frac{\sigma_{01} \cdot p_{0} \cdot \pi_{c}}{R} \cdot \frac{\sigma_{22^{*}}}{\left\{T_{0} \cdot\left[\frac{\pi_{c}^{\frac{\kappa_{a}-1}{\kappa_{a}}}-1}{\eta_{i s c}}+1\right]\right\} \cdot(1-\phi)+\phi \cdot T_{0}}
\end{aligned}
$$

\subsection{The change of indicated mean pressure of the supercharged engine due to the positive area of scavenging in $\mathrm{p}-\mathrm{V}$ diagramand back pressur of exhaust gases}

The increase of indicated mean pressure of the supercharged engine is definitively depending on the $\rho_{2}$ density. The value of $p_{i c h}$ is influenced in a significantly less extent by the $\left(p_{2}-p_{3}\right)$ pressure differential assuming $p_{2}>p_{3}$.

Without using intercooler the $p_{\text {iex }}$ indicated mean pressure arising from back pressure $\left(p_{2}-p_{3}\right)$ and scavenging:

$$
p_{\text {iex }}=\left(p_{2}-p_{3}\right)-\left(p_{3}-p_{0}\right)
$$

Using an intercooler the above equation takes the form of:

$$
p_{\text {iex }} *=\left(\sigma_{22^{*}} \cdot p_{2}-p_{3}\right)-\left(p_{3}-p_{0}\right)
$$

The $p_{i e x}{ }^{*}$ indicated mean pressure is slightly reduced (0.4$0.6 \%$ ) due to the pressure loss of the intercooler.

As a consequence of the back pressure of the exhaust turbine the indicated mean pressure of the turbocharged engine is decreased with the value of $\left(p_{3}-p_{0}\right)$, however, the power requirement of the compressor should not be subtracted as it should be done with the mechanically driven superchargers. The pressure difference $\left(p_{3}-p_{0}\right)$ reduces the indicated mean pressure by $4-5 \%$; nevertheless, this decrease is significantly less compared to the power requirement of the compressor. This is one of the advantages of turbocharging.

The total cycle indicated mean pressure can be calculated as:

$$
p_{\text {icht }}=p_{\text {ich }}+p_{\text {iex }} ; \quad p_{i c h t}^{*}=p_{\text {ich }}+p_{i e x}^{*}
$$

Besides the increment of indicated mean pressure by some percent the effect of more perfect scavenging is of a higher importance due to valve overlap. It has a substantial relevancy on the reducing thermal loading of the engine and improving its service life (Fülöp, 1990).

The detailed description of the above mentioned effects would reach beyond the limits of the present work; however, the determination of the $p_{3}$ pressure is included.
Under steady state conditions the turbocharger operates in a thermodynamic balance condition, i.e. $W_{C}=W_{T}$ that can be written as follows, regarding the notation of Figures 2 and 3:

$$
c_{p g} \cdot m_{g} \cdot\left(T_{3}-T_{4}\right)=c_{p a} \cdot m_{a} \cdot\left(T_{2}-T_{1}\right)
$$

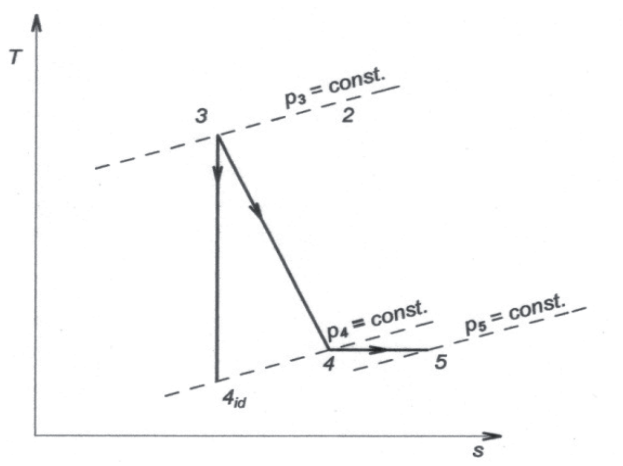

Fig. 3. T-s diagram of expansion process

Taking into account the isentropic efficiencies for the compressor and turbine and the $\eta_{m}$ mechanical efficiency of the turbocharger, including the compressor pressure ratio $\pi_{C}=p_{2} / p_{1}$ and turbine pressure ratio $\pi_{T}=p_{3} / p_{4}$, and raising the known temperatures of $T_{1}$ and $T_{3}$, one can obtain:

$$
\begin{aligned}
& c_{p g} \cdot 1,02 \cdot m_{a} \cdot T_{3} \cdot \eta_{i s t} \cdot \eta_{m} \cdot\left(1-\frac{1}{\pi_{T}^{\frac{\kappa_{g}-1}{\kappa_{g}}}}\right) \\
& =\frac{c_{p a} \cdot m_{a} \cdot T_{1}}{\eta_{i s C}} \cdot\left[\left(\pi_{C}\right)^{\frac{\kappa_{a}-1}{\kappa_{a}}}-1\right]
\end{aligned}
$$

The amount of air, what has been delivered by the compressor, is reducing by some $1 \%$ due to sealing losses between the piston and its sleeve. On the contrary, the gas mass through the exhaust turbine is increasing the previous value by $2 \%$ because of the fuel supply; the consequence is the approximation of $m_{g} \approx 1.02 \cdot m_{a}$ relationship which strongly depends on the engine health.

Introducing the simplified annotation of $\eta_{i s C} \cdot \eta_{i s T} \cdot \eta_{m}=\eta_{\text {is tot }}$ and taking into account that $p_{4}=p_{5} / \sigma_{45} ; p_{1}=p_{0} \cdot \sigma_{01}$, the value for $p_{3}$ can be expressed.

When investigating the Equation (15) one can see the advantage of the introduction of $\eta_{i s ~ t o t}$, which is combining the three individual factors to a single "total" efficiency, while using polytropic exponents or efficiency similar possibility is not given. The $p_{3}$ pressure is influenced by the product of the three factors, independently of their components. 


\section{Results of the investigation and their evaluation} 3.1 Initial data of the investigation and their correlations

The increase of $p_{\text {icht }}$ total indicated mean pressure of the engine is determined by Equations (4/a); (11) and (13). In the investigation the following parameters have been taken into consideration.

a) Isentropic efficiency of the compressor $\left(\eta_{i s}\right)$. Its value has been changed in the range of $0.67-0.78$. The $\eta_{i s c}<0.65$ results in a rather poor effect of supercharging; values over 0.78 can be achieved only in turbochargers of relatively large engines (e.g. maritime engines). The utilization of axial compressors is practically impossible.

b) Isentropic efficiency of the turbine $\left(\eta_{i s} T\right)$, which has some $2 \%$ larger value in contrast to the compressor. The aerodynamic details of this effect cannot be discussed here.

c) The mechanical efficiency of the turbocharger $\eta_{m}$ has been used as a constant parameter with a value of $\eta_{m}=0.98$. According to the previously mentioned thoughts, the $\eta_{\text {istot }}$ total efficiency is containing the following products. The value $\eta_{\text {istot }}=0.6$ can be regarded as the maximum achievable limit, which could not be exceeded in the future due to the inevitable friction and incidence losses.

\begin{tabular}{ccccc}
\hline$\eta_{\text {is } C}$ & 0.671 & 0.707 & 0.742 & 0.775 \\
$\eta_{\text {is } T}$ & 0.685 & 0.721 & 0.757 & 0.791 \\
$\eta_{m}$ & 0.98 & 0.98 & 0.98 & 0.98 \\
$\eta_{\text {istot }}$ & 0.45 & 0.5 & 0.55 & 0.6 \\
\hline
\end{tabular}

d) The compressor pressure ratio $\eta_{c}$ has been varied in the range of 1.5 and 3.5. Pressure ratios $\eta_{c}<1.5$ can be supposed as resulting unsatisfactory supercharging conditions while $\eta_{c}>3.5$ is rather high and is not widely utilized in commercial engines produced in large numbers.

e) The turbine inlet temperature $t_{3}$ (see Figures 1 and 3) is an essential factor of turbocharging efficiency. The $t_{3}$ temperature cannot be taken arbitrarily; it depends primarily on the turbocharged engine thermal loads and its construction (Mayer, 1996a). Based on other investigations, the extremely low speed maritime engines including water cooled exhaust duct can reach a minimum of $t_{3} \approx 450^{\circ} \mathrm{C}$, while high speed engines of road transport vehicles can operate with $t_{3} \approx 800-850^{\circ} \mathrm{C}$. Excluding the two extreme cases we have taken into account $t_{3}$ values of 500,600 and $700^{\circ} \mathrm{C}$ in our calculations.

f) Those pressure loss factors, which are influencing the efficiency in a moderate extent, have been assumed having a constant, realistic value. According to Figure 1 (see definitions in the list of symbols):

$$
\begin{gathered}
\sigma_{01}=\frac{p_{1}}{p_{0}}=0,98 ; \\
\sigma_{22^{*}}=\frac{p_{2}^{*}}{p_{2}}=0,99 ;
\end{gathered}
$$

$$
\sigma_{45}=\frac{p_{5}}{p_{4}}=0,98
$$

g) During the evaluation of our results we have used the $p_{i c h t} / p_{i 0}$ ratio instead of the total indicated mean pressure $p_{\text {icht }}$ of the supercharged engine. As of our considerations, this ratio presents the tendency of changes better than the $p_{\text {icht }}$ pressure itself. The base engine of our investigation has a $p_{i 0}$ indicated mean pressure of $1.1 \cdot 10^{6} \mathrm{~N} / \mathrm{m}^{2}=11$ bar. This corresponds to the category of an engine of common automobiles.

\subsection{The increase of total indicated mean pressure of the supercharged engine without intercooler}

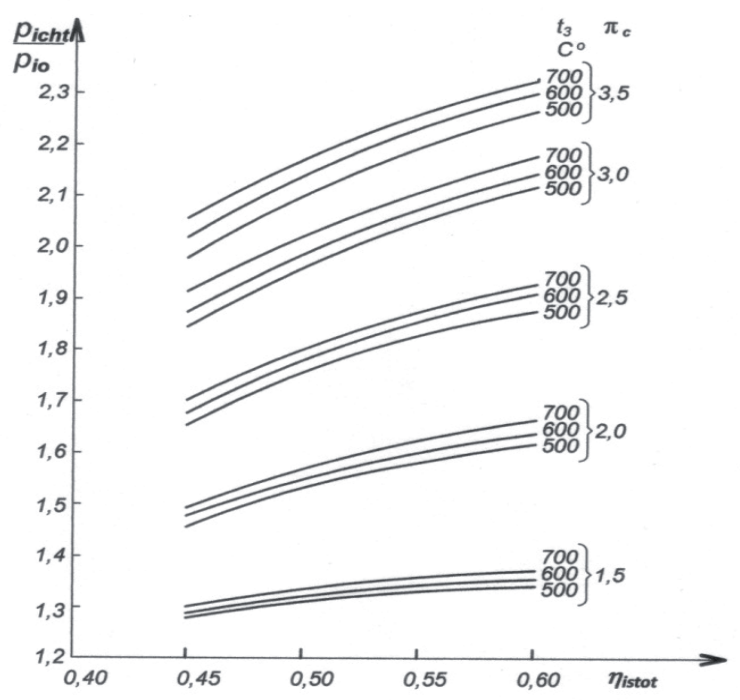

Fig. 4. Effectiveness of supercharging (ratio of indicated mean pressures of supercharged and basic engines) as a function of total efficiency $\eta_{\text {istot }}$ at different $\pi_{c}$ compressor pressure ratios and $\mathrm{t}_{3}$ turbine inlet temperatures without intercooling

On Figure 4 one can see the $p_{\text {icht }} / p_{i 0}$ ratio for a supercharged engine without intercooler as the function of $\eta_{\text {istot }}$ with various $\pi_{c}$ pressure ratios and $t_{3}$ turbine inlet temperatures. The rise of each of the three parameters cause a significant increase in the degree of supercharging, which shows an intensive growth when $\eta_{\text {istot }}$ is improved at high pressure ratio, but its tendency is diminishing, consequently the favorablevalue of $\eta_{i s t o t}$ is extremely important under such circumstances. The increase of $t_{3}$ turbine inlet temperature clearly raises the degree of supercharging, but the ratios are not modified substantially.

The approximate change of

$$
\Delta\left(\frac{p_{\text {icht }}}{p_{i 0}}\right) / \Delta \eta_{\text {istot }}
$$

gradient is shown as a function of $\pi_{c}$ on Figure 5. It is only an approximation due to the omitted minimal effect of change in $t_{3}$. 


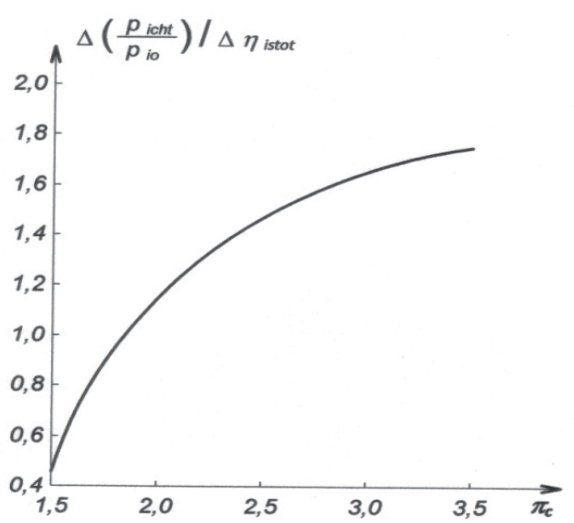

Fig. 5. Approximate change of gradient $\Delta\left(\frac{p_{i c h t}}{p_{i 0}}\right) / \Delta \eta_{i s t o t}$ as a function of pressure ratio $\pi_{c}$ without intercooling

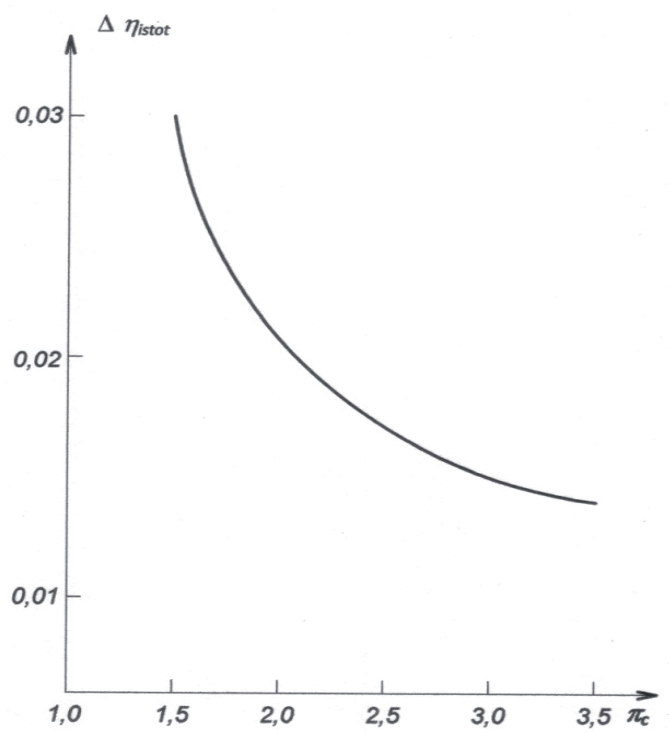

Fig. 6. Possible reduction of total efficiency $\Delta \eta_{\text {istot }}$ due to turbine inlet temperature increase $\Delta t_{3}=100^{\circ} \mathrm{C}$ as a function of pressure ratio $\pi_{c}$

According to the consequences drawn evaluating Figure 4, taking into account a constant $\Delta \eta_{i s t o t}$ change in the efficiency, the effectiveness of the supercharging rises monotonously as the function of $\pi_{c}$, but the tendency of growth is declining. As it can be stated by evaluating Figures 4 and 5, it is not economic to increase $\pi_{c}$ above 3.5-4 without intercooler, due to the relative drop in the efficacy. This negative effect is caused by the strong increase in $T_{2}$ compressor discharge temperature with the rising $\pi_{c}$, if one omits the intercooler, resulting in the relative decrease in the density of the compressed air.

According to Figure 4, the reduction in $\eta_{i s t o t}$ can be compensated by the rise of turbine inlet temperature $t_{3}$. The same conclusion can be investigated on Fig. 6 with the help of other parameters, where the drop of $\Delta \eta_{\text {istot }}$ can be seen as the function of $\pi_{c}$ caused by a temperature increase of $\Delta t_{3}=100^{\circ} \mathrm{C}$. As stated by Fig. 6 , in the intermediate range of $\pi_{c}=2-2.5$ the reducing efficiency of $\Delta \eta_{\text {istot }} \approx 0.02-0.017$ can be compensated with the above mentioned increase in turbine inlet temperature $t_{3}$. The diagram indicates average changes, although the conditions are hardly depending on the selection of the value of $\Delta \eta_{\text {istot }}$ from the available $\eta_{\text {istor }}$ ranges, according to our investigation. In another viewpoint, the $\Delta \eta_{\text {istot }}$ shows a decreasing tendency with increasing $\pi_{c}$ to offset the effect of turbine inlet temperature increase of $\Delta t_{3}=100^{\circ} \mathrm{C}$. This is a result of the rise of $p_{\text {icht }} / p_{i 0}=f\left(\eta_{\text {is tot }}\right)$ gradient, as shown on Fig. 4.

The largest problem is that the turbine inlet temperature $t_{3}$ cannot be modified arbitrarily; it is a function of many parameters of the turbocharger and the supercharged engine, which are frequently inconsistent with each other, but the $t_{3}$ temperature depends on the thermal load of the supercharged engine. This problem is so complicated that its detailed discussion cannot be covered herein. We return to this subject in terms of scavenging (Dezsenyi et. al., 1990).

\subsection{Using an intercooler downstream of the compressor}

The positive effect of cooling the airflow, which is supplied by the turbocharger compressor at a temperature of $t_{2}$, is clear. The basic diagram of the intercooled instance is shown on Fig. 7, which is strongly similar in comparison with Fig. 4; the only important difference is that the process takes place at an elevated level. In order to accentuate the positive changes, Fig. 7 does not show the absolute value of $p_{\text {icht }}^{*}$ for the intercooled turbocharged engine having an intercooler efficiency factor of $\varphi$, but the ratio of change in contrast to the case without intercooler $(\varphi=0)$. According to this, on the ordinate axis of Fig. 7 the measure is $\left(p_{\text {icht }}^{*} / p_{\text {icht }}\right)=P$. On Fig. 7 , this is denoted as $P$. In order to increase perspicuity of Fig. 7 it contains only the case for $t_{3}=600^{\circ} \mathrm{C}$, as $P$ is hardly influenced by $t_{3}$.

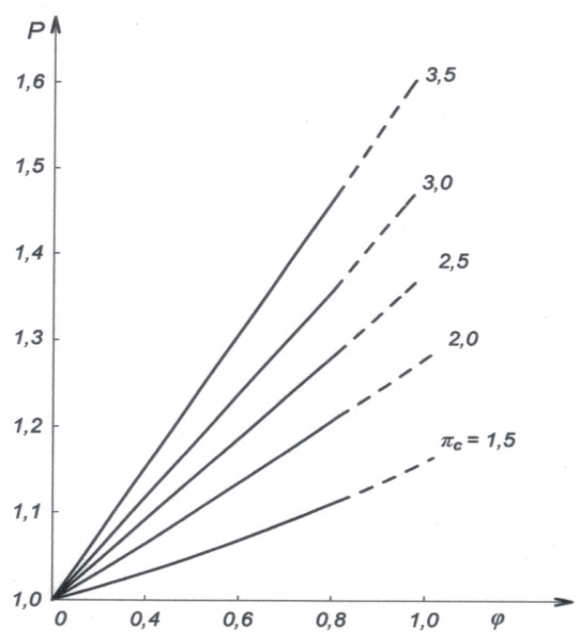

Fig. 7. Change of ratio $P=\left(p_{\text {icht }}^{*} / p_{\text {icht }}\right)$ as a function of $\varphi$ heat exchange factor at $t_{3}=600^{\circ} \mathrm{C}$ and various $\pi_{c}$ compressor pressure ratios 
The intercooler heat exchange factor $\varphi$ has a maximal value of approximately $\varphi \approx 0.8$. Values above this level cannot be realized, even with rotating (regenerative) heat exchangers (Fülöp, 1975), except that the installation of heat exchangers in automobiles is always a problem. On Fig. 7, one can clearly see the extremely beneficial effect of intercooling and the fact, that intercooling is worthy only with relatively large values of $\pi_{c}$. Assuming an average heat exchange factor $(\varphi \approx 0.5-0.6)$ and a compressor pressure ratio of $\pi_{c}=3.5$, the achievable increase in engine power is approximately $26-28 \%$.

The heat exchange factor $\varphi>0.8$ might be realized with one type of air cycle machines (Pásztor, 1977; Pásztor, 1981). Although these devices are very useful, they are rather heavy and their dimensions are also excessive. As the effective efficiency of the supercharged engine is rather diminishing, than increasing using these units, their spread is quite limited. The deterioration of effective efficiency results from the power requirement of the negative cooling cycle.

The favorable effect of intercooling manifests itself in the increasing efficacy of the scavenging (internal cooling of the engine) besides the rise of effective power. This effect cannot be easily represented numerically, but this leads to a significant growth in the service life of the supercharged engine, especially when large level of supercharging is used. There is a less important impact of intercooling, namely the decrease in the temperature of the incoming air leads to a proportionally diminishing power requirement for the compression (in the engine cycle) while the indicated mean pressure increases by some percent. The ideal process is depicted by Fig. 8 . It is independent of the sign of the area of scavenging in the $\mathrm{p}-\mathrm{V}$ diagram, but its effect is damped by the warming of the air inside the engine.

\subsection{Area of scavenging in $\mathrm{p}-\mathrm{V}$ diagram}

\section{as a function of turbocharging parameters}

The area of scavenging in the $\mathrm{p}-\mathrm{V}$ diagram strongly influences the service life of the engine due to internal cooling as well as the removal of residual gases from the previous combustion process. According to these ascertainments, a slightly more detailed investigation follows.

The area of scavenging has a positive sign if $p_{2}>p_{3}$. The value of pc has a clear impact on the magnitude of $p_{2}$, while $p_{3}$ comes from the thermodynamic equilibrium of the turbocharger rotor $\left(W_{c}=W_{t}\right)$ as described by Eq. (15). The starting values are included in the list of symbols. The positive area of scavenging decreases if $\eta_{i s t o t,}, t_{3}$ and $\pi_{c}$ are reducing; and, as it is shown on Fig. 9, it can turn into a negative area. As of our investigation, assuming an average $t_{3}=600^{\circ} \mathrm{C}$ and $\pi_{c}=2.5$, a minimum of $\eta_{\text {istot, }}=0.5$ is required to achieve a significantly positive area for scavenging. Taking into account a small turbocharger with relatively small air mass flow $\left(\eta_{i{ }_{C}} \approx 0.7\right.$; $\eta_{i s T} \approx 0.73 ; \eta_{m} \approx 0.98$ ) the above mentioned total isentropic

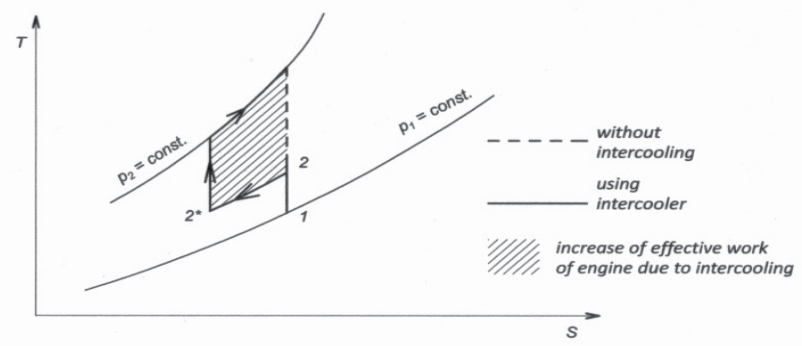

Fig. 8. Effect of intercooling on the compression process of the turbocharged engine (dashed - without intercooling; solid - using intercooler; hatched area - increase of effective work of engine due to intercooling)

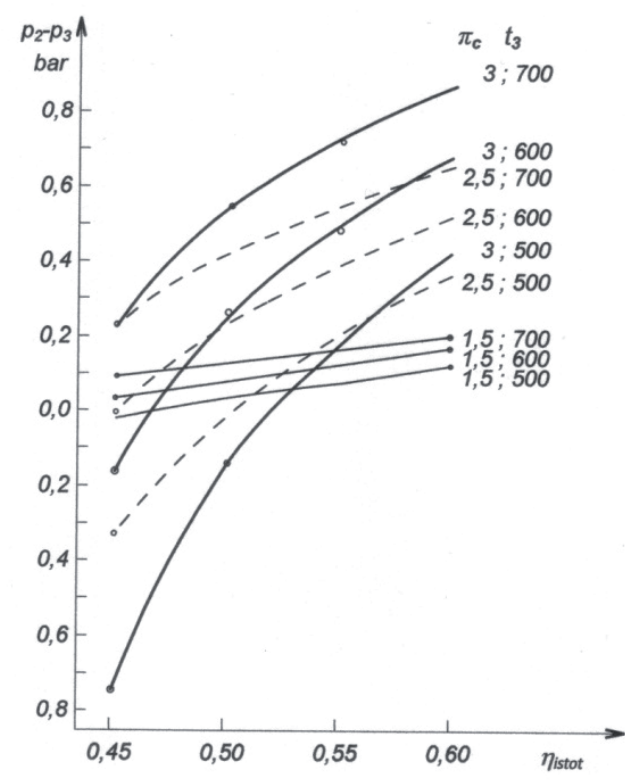

Fig. 9. Change of $\left(p_{2}-p_{3}\right)$ scavenging pressure difference as a function of $\eta_{\text {istot }}$ at different $\pi_{c}$ pressure ratios and $t_{3}$ turbine inlet temperatures

efficiency is difficult to reach, here the utilization of so called "impulse" supercharging (Mayer, 1996b; Dezsényi et. al., 1990) is getting more significant, which helps to achieve slightly more favorable conditions. The detailed discussion of this method is not possible to fit within the limits of the present work. Returning to Fig. 9, one can see that in order to provide easy evaluation only $\pi_{c}=1.5 ; 2.5$; and 3.5 are indicated, due to the intersection between the curves.

On Fig. 10 those $\pi_{c}$ values have been collected, which result in a $\left(p_{2}-p_{3}\right)=0$ condition as the function of $\eta_{\text {istot }}$. The relatively large $\pi_{c}$ requires very high $t_{3}$ turbine inlet temperature and favorable $\eta_{\text {istot }}$ efficiency in order to maintain the difference $\left(p_{2}-p_{3}\right)$ over zero. From the two latter figures one can draw the consequence that in the higher range of $\pi_{c}\left(\pi_{c}>2.5-3\right)$, only the high $\eta_{i s t o t}$ efficiency allows favorable properties of turbocharging. In order to improve this process the increase in $\mathrm{t} 3$ would be necessary, but, as it has been stated before, it is a dependent parameter of the complete supercharging cycle and cannot be varied alone arbitrarily. 


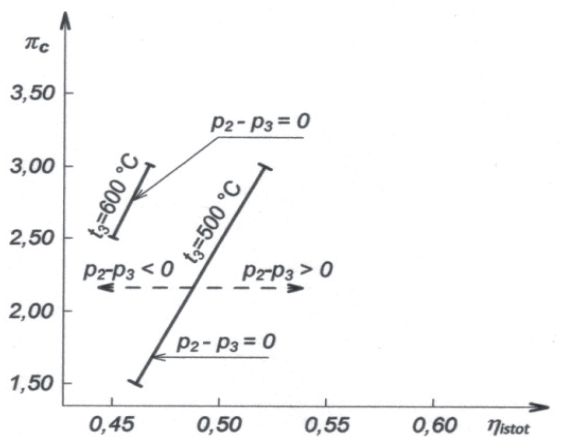

Fig. 10. Figure 10 Zero value $\left(p_{2}-p_{3}\right)$ scavenging pressure difference as a function of $\eta_{\text {istot }}$ at $\mathrm{t}_{3}=500^{\circ} \mathrm{C}$ and $600^{\circ} \mathrm{C}$. At $\mathrm{t}_{3}=700^{\circ} \mathrm{C}$, there is no zero point

\section{Conclusions}

- Assuming medium $\eta_{\text {istot }}$ and $\pi_{c}$ the achievable increment in the power of turbocharged engine without intercooling falls in the range of $70-75 \%$ in contrast to the basic engine.

- Taking into consideration maximal values of $\eta_{\text {istot }}$ and high $\pi_{c}$, the aforementioned increase can reach $100-120 \%$. This is the ultimate limit without intercooler.

- Without intercooler the degree of supercharging increases significantly for a unit $\eta_{i s t o t}$ if the $\pi_{c}$ pressure ratio is rising, but in tendency its measure is reducing.

\section{References}

Beneda K. (2013) Development of Active Surge Control Devices for Centrifugal Compressors. PhD dissertation. Budapest.

Bosnjakovic F. (1972) Technical Thermodynamic [In German: Technische Thermodinamik]. Dresden: Verlag Theodor Steinkopff.

Boyce M. P. (1993) Principles of Operation and Performance Estimation of Centrifugal Compressors. Proceedings of the $22^{\text {nd }}$ Turbomachinery Symposium, Texas A \& University. pp. 161-177. [Online] Available from: http://turbolab.tamu.edu/proc/turboproc/T22/T22161-177.pdf [Accessed: 15 $5^{\text {th }}$ March 2013]

Dezsényi Gy. et al. (1990) Design and analysis of internal combustion engines [In Hungarian: Belsőégésü motorok tervezése és vizsgálata]. Budapest: Tankönyvkiadó.

Fülöp Z. (1975) Gasturbines [In Hungarian: Gázturbinák]. Budapest : Müszaki Könyvkiadó.

Fülöp Z. (1990) Internal Combustion Engines [In Hungarian: Belsöégésü motorok]. Budapest: Tankönyvkiadó.

Kalabic V. et al. (2011) Reference and Extended Command Governors for Control of Turbocharged Gasoline Engines Based on Linear Models. 2011 IEEE International Conference on Control Applications. September 28-30. pp. 319-321. DOI: $10.1109 / C C A .2011 .6044457$

Mayer M. (1996a) Turbochargers. Landsberg/Lech: Verlag Moderne Industrie.
- Assuming average $\pi_{c}$ and efficiency increase $\Delta \eta_{\text {istot }}$ equal to unity, the degree of supercharging grows by 1.25 without intercooling.

- The increase in turbine inlet exhaust gas temperature $t_{3}$ can offset the effect of the reducing $\eta_{\text {istot }}$ but the intensity of compensation is diminishing as $\pi_{c}$ increases. Taking into account an average $\pi$, one can state that a reduction of $\Delta \eta_{\text {istot }}=0.2$ can be compensated by the growth of $t_{3}$ of $100^{\circ} \mathrm{C}$.

- The effectiveness of intercooling is strongly depending on $\pi_{c}$; a system with average $\pi_{c}$ and $\varphi$ the achievable additional degree of supercharging is approximately $20-25 \%$. Assuming a very high $\pi_{c}$ and favorable $\varphi$ the additional degree of supercharging can reach a maximum of about $45 \%$. The values over this limit can be realized only with additional cooling cycles.

- The $\left(p_{2}-p_{3}\right)$ pressure difference of scavenging depends extremely strongly on the three major parameters $\eta_{\text {istot }} ; \pi$; $t_{3}$ ). Its important feature is that its sign changes rapidly to negative if $\pi_{c}$ is high while only moderate $t_{3}$ is achievable.

- Supposing an average value for pc and a moderate t3, the minimum of $\eta_{\text {istot }}=0.5$ is necessary to maintain the pressure difference $\left(p_{2}-p_{3}\right)$ in the positive range or at least at zero.

Mayer M. (1996b) Turbochargers. Effective use of exhaust gas energy. Landsberg/Lech: Verlag Moderne Industrie.

Pásztor E. and Szoboszlai K. (1967) Operation of caloric machines [In Hungarian: Kalorikus gépek üzeme]. Budapest : Müszaki Könyvkiadó

Pásztor E. (1970) Investigation of connection between efficiency and work process of internal combustion engines [In Hungarian: Belsöégésü motorok munka- folyamata és mechanikai hatásfoka közötti kapcsolat vizsgálata]. Thesis of Hungarian Academy of Sciences [In Hungarian: Akadémiai doktori értekezés] Budapest.

Pásztor E. (1977) Analyse des Arbeitsprozessen von Kältemaschinen mit Luftzyklus und ihre Anwendungsmöglichkeiten. [In German: Analyse des Arbeitsprozessen von Kältemaschinen mit Luftzyklus und ihre Anwendungsmöglichkeiten]. Acta Technica, Tomus, 84 (3-4), Budapest: Verlag der Ungarische Akademie der Wissenschaften.

Pásztor E. (1981) Turbo Coolers and their theoretical nad practical performance [in German: Grubenturboluftkühler-Ihre Theorie und praktische Ausführung] Acta Technica, Tomus 93 (3-4).

Siwale L. et al. (2013) Combustion and emission characteristics of n-butanol / diesel fuel blend in a turbo-charged compression ignition engine. Fuel, 107, pp. 409-418.

DOI: 10.1016/j.fuel.2012.11.083 